\title{
Coordinated Headway-Based Control Method to Improve Public Transit Reliability considering Control Points Layout
}

\author{
Hu Zhang, Shidong Liang $(\mathbb{D}$, Jing Zhao, Shengxue He, and Tianyu Zhao \\ Department of Traffic Engineering, University of Shanghai for Science and Technology, Shanghai, China \\ Correspondence should be addressed to Shidong Liang; sdliang@hotmail.com
}

Received 21 November 2019; Revised 22 March 2020; Accepted 4 June 2020; Published 9 July 2020

Academic Editor: Tao Liu

Copyright (C) $2020 \mathrm{Hu}$ Zhang et al. This is an open access article distributed under the Creative Commons Attribution License, which permits unrestricted use, distribution, and reproduction in any medium, provided the original work is properly cited.

\begin{abstract}
The headway-based control method is usually used to regulate the bus headways and improve reliability of public transit. In general, the holding control strategy is applied at the control point, because enough space for dwell longer at the control point is required, while the stop-skipping control strategy can be used at any bus stop. However, in the headway-based control method, too much stop-skipping will bring longer waiting time and make the passengers impatient. The number and distribution of control points for stop-skipping are not considered in previous self-equalizing bus headway control works. Therefore, in this paper, the control points selection rules for stop-skipping involving their number and distribution on the bus route are discussed. A second by second discrete system is formulated to describe the bus operation. In the proposed control method, the threshold value for activating stop-skipping strategy is raised, avoiding provoking much additional waiting time because of boarding rejected. In the numerical analysis, a set of cases are conducted to evaluate the performance of control method under different number and distribution of control points for stop-skipping. The numerical results show that distribution of control points for stop-skipping has a greater influence on the public transit than the number.
\end{abstract}

\section{Introduction}

Bus bunching is a phenomenon when two or more buses encounter the same bus stop on a bus line, and it commonly appears in an unstable high-frequency bus line system. If a bus running on a bus route is delayed by an incidental disturbance, this bus should pick up more passengers than expected at the downstream bus stop. Therefore, the bus should dwell longer than expected and further gets delayed because of more boarding passengers at the bus stop. Meanwhile, its following bus runs closer to the leading bus and meets less number of passengers at the bus stop; therefore, it is speeded up because of shorter dwell time than expected. The leading bus gradually slows down, while the following bus speeds up, resulting in the two successive buses arriving at a same bus stop at the same time or in a very short time interval inevitably.

Bus bunching results in longer waiting and travel times for the passengers and the increased environment pollution due to inefficient operation of unevenly loaded buses. In addition, the unbalanced load of passengers on successive buses wastes bus capacity, because the leading bus is quite crowded while the trailing bus is relatively empty.

To resist bus bunching, many control methods were proposed in previous related works. With the advent of new technologies, some holding strategies have been proposed to take advantage of real-time information so as to reduce passengers' waiting times $[1,2]$. Using real-time information, many headway-based holding strategies have been proposed to adaptively control the system [3-13]. A "twoway-looking control" bus headway control method was proposed by Daganzo [14]. This method attempts to make the headways presettled static values. Later, Daganzo and Pilachowski [15] proposed a control strategy that continuously adjusts the bus's cruising speed on the route based on a cooperative two-way system to achieve proper spacing between the successive buses on the line. As an extension of this control concept, Xuan et al. [16] and He [6] proposed a holding strategy to regularize headways while maximizing the commercial speeds, as well as considering both the forward and backward headways. Bartholdi and Eisenstein 
[4] proposed a self-adaptive control method to automatically equalize bus headways on the bus route. To integrate the advantages of the "two-way-looking control" and the "selfadaptive equalizing bus headway," Liang et al. [17] proposed a self-equalizing control strategy based on the two-waylooking control method (the headways between the bus at the control point and both its leading and following buses) with zero slack. Zhang and Lo [18] proposed two-waylooking self-equalizing headway control that considered multifarious variables, enriching the headway-based bus holding control method system. More recently, He et al. [19] and Liang et al. [20] proposed a dynamic target headwaybased control method to resist bus bunching with holding strategy, which is another version of self-equalizing bus headway control method.

However, in the self-adaptive equalizing bus headway control method system, only one holding control means was used. Bus holding is based on slowing the faster leading bus and increasing the slack to balance headways, thus decreasing the average operating speed of the total bus system to resist bus bunching. Therefore, other control means at the control point can be integrated with bus holding to enhance the performance of control method based on the selfadaptive equalizing bus headway control concept. Stopskipping strategy is used in which a bus is asked to skip a stop as long as nobody inside the bus requests to stop, even though there are passengers at the bus stop waiting to board the bus. Different criteria such as the operational costs, average waiting time, and passenger awareness are considered to determine which stops should be skipped. In the early work on rail systems by Suh et al. [21], a stop-skipping strategy was utilized to increase the speed of subway service. Sun and Hickman [22] proposed a stop-skipping strategy to minimize the passenger waiting times but allowed the passengers to alight at stops in the skipped segment. A multiobjective optimization approach for stop-skipping strategies was addressed by Sidi et al. [23]. Cortés et al. [24] and Sáez et al. [25] developed a hybrid predictive control formulation that jointly estimates the bus speed, while implementing control strategies such as skipping stations or holding buses. Delgado et al. [5] addressed the combination of holding strategies with boarding limits. The authors developed a deterministic optimization model capable of executing two strategies: holding and boarding limits (limiting the amount of passengers that can board a bus even if the bus is not at full capacity); this control strategy was also used by [26]. In recent years, Zhang et al. [27, 28] and Wu et al. $[29,30]$ proposed a set of limited-stop control methods to deal with stochastic travel time and uncertain demand.

The holding control means should be implemented at the bus stops selected as control points, because the control point should provide enough space for bus to dwell longer, while the stop-skipping control means can be used at any bus stop. However, the stop-skipping control method will provoke more waiting time. Therefore, in this paper, the integrated control method involving bus holding and stopskipping control means is proposed based on the selfequalizing bus headway control concept. The method that integrated "two-way-looking control" with "self-adaptive equalizing bus headway" has been proven to perform well in reducing bus bunching and improving the service level for passengers. However, the control concept cannot be implemented completely in the proposed integrate control method, because the stop-skipping is a strong control means which will provoke dissatisfaction of passengers who are rejected to board. Therefore, the priority of activating stopskipping is reduced, with higher threshold value, giving consideration to both performance of equalizing bus headways and feeling of passengers.

The remainder of this paper is organized as follows. In Section 2, the coordinated control algorithm is proposed to dynamically select the two control means based on predictive control. In Section 3, the buses' operation process has been described by formulated as a discrete system. The operation rules are divided into operation at normal bus stop and control point, respectively. In Section 4, two kinds of performance indexes are proposed to reflect the regulation of bus operation and the condition of passengers on the buses. A set of numerical tests are conducted in Section 5, using the proposed coordinated control method under different number and distribution of control points for stopskipping.

\section{Self-Equalizing Bus Headways Control Strategy with Two Control Means}

In this section, a dynamic control strategy was developed to equalize bus headways, resisting bus bunching. A dynamic selection algorithm of control means including bus holding, stopskipping, and no control means was implemented. The control variables, e.g., holding time, can be calculated by analysing both the real-time bus running status and passenger demand. In order to distinguish the control point for bus holding only, stopskipping only, and coordinated control, $\mathrm{CPH}$ (control point for holding), CPS (control point for stop-skipping), and CPC (control point for coordinated control), respectively, are named. The coordinated control method, used at CPC, involves holding control strategy and stop-skipping control strategy. In practice, these control strategies should be selected dynamically according to the algorithm shown in Section 3.3.

\subsection{Motivation of Proposing the Coordinated Control Method.} The coordinated control method proposed in this paper is derived from the control concept of self-adaptive equalizing bus headways proposed in Liang et al. [17, 31], which is suitable to be applied to a high-frequency bus route. A self-adaptive method to equalize headways based on bus holding was tested and proved to perform well to reduce slack time and enhance operation efficiency. However, successive bus headways at control point cannot be equalized completely using bus holding only, because bus holding is insufficient when the forward headway is larger than the backward headway; thus the bus holding cannot speed up the slow bus. Recently, Liang et al. [32] fixed this gap by integrating the two control means into selfadaptive equalizing bus headways framework. According to the test results compared with bus holding used only, the coordinated control method can shorten total travel time and make 
bus headways more regular. However, the waiting time increased because of stop-skipping control means. Therefore, in order to decrease the negative effects brought by stop-skipping control means, in this paper, it is treated as a supplementary means. When the headways between the bus at control points and the following bus are much smaller than the bus headway with leading bus, the stop-skipping control means shall be used. In other word, the stop-skipping will be activated with higher threshold value, giving consideration to regular bus operation and passengers' experience.

In fact, other control strategies, i.e., speed control and schedule recovery, can achieve similar control result. However, the speed control is usually used on bus lanes, without disturbance of cars on the street [33]. Therefore, in this paper, the speed control is not considered as supplement to holding control strategy. Although schedule recovery control concept is quite useful in practice to regulate bus operation, it is not suitable to be integrated as a supplement strategy in the self-equalizing control concept.

In traditional research, the stop-skipping control is a static schedule to improve operation efficiency of bus system instead of a dynamical control means to control the bus. Boarding limits can accelerate the bus at control point, while the following bus can be slowed down by leaving more passengers to it. However, in practice, it is not easy to refuse part of passengers waiting at the bus stop to get on the bus even when the bus is not full. Therefore, stop-skipping in this paper refers to the bus only providing service for alighting passengers when the control point is skipped, proposed by Sun and Hickman [22]. This kind of stop-skipping control method can speed up the slower bus through dwelling shorter time and meanwhile slow down the faster bus by giving it more passengers to pick up. In addition, the passengers on the bus can alight at any bus stops, avoiding missing the destination bus stop and causing dissatisfaction of passengers.

If the bus headways are quite equalized, the bus at the CPC should not be controlled with any control means. We term such a condition as "no control means." Therefore, three control means can be used at the CPC which are bus holding, stopskipping, and no control means. The core of the coordinated control method is to dynamically select proper control means to equalize the bus headways, according to the prediction of control results. Because studies that predict the related parameters in bus systems are relatively mature [34-41], the evolution of bus systems can be predicted with these methods in practice. In addition, the estimations of urban traffic parameters are also sufficiently mature, e.g., travel speed and queue length at signalized intersection [42-45]. Therefore, the main objective of this section is to propose a method that combines the bus holding control means and stop-skipping control means based on the self-adaptive equalizing headways control concept. The detailed control strategy and algorithm are introduced in the following subsection.

\subsection{Control Strategy Coordinated Control Means at CPC.} When a bus has just arrived at the CPC, it should judge whether the stop-skipping control means is suitable to be used to equalize the bus headways. If the stop-skipping control means is selected to be used, the bus can leave the $\mathrm{CPC}$ directly after letting the passengers alight. If the stopskipping control means is not suitable to be used, the bus can provide normal service for the passengers on the bus and wait at the CPC. After the normal service, it should be judged whether the bus holding control means is suitable to be used to equalize the bus headways. If the holding control means is not suitable to be used, the bus can leave the CPC. Otherwise the bus should dwell at the CPC for suitable additional time.

Note that the stop-skipping control means should be considered when the bus has just arrived at the CPC, and the bus holding should be considered after the bus providing service, because the predictive values of headways can be more accurate due to shorter prediction step length.

According to the previous research conclusion by Liang et al. $[17,31,32]$, the bus headways can be convergent to a common value after continually equalizing the two bus headways between the bus at CPC and its leading and following buses. Therefore, we only focus on three buses (i.e., the bus arriving at CPC and its leading and following buses) at a moment, as shown in Figure 1. We define the bus headway as the time between two successive buses leaving the same bus stop. According to this definition, the bus headway between the bus at CPC and its leading bus can be predicted after the bus at the CPC leaving current bus stop, named $\widetilde{h}_{l}$. The bus headway between the bus at CPC and its following bus can be predicted after the following bus leaving CPC, named $\widetilde{h}_{f}$. The selection of variable control means can be obtained through comparing the $\widetilde{h}_{l}$ and $\widetilde{h}_{f}$ under different control means. Concretely, the control process at CPC for both bus holding and stop-skipping is shown in Figure 2.

Note that, according to the research results of Liang et al. [32], based on this control principle, the stop-skipping control means was used relatively frequently increasing the waiting time of passengers. In order to decrease the additional waiting time of passengers and maintain the regular bus headway of public transit, in this paper stop-skipping is treated as a supplementary means whose priority is lower than bus holding and no control means. If the difference of two bus headways at the CPC is relatively large, the stopskipping control means can be used. More exactly, in this paper if the following bus headway $\widetilde{h}_{f}^{\text {ss }}$ controlled by stopskipping means is still smaller than the leading bus headway $\widetilde{h}_{l}^{\text {ss }}$, the stop-skipping control means should be used. According to this control principle, the stop-skipping control means was used less and ensured large difference of successive bus headways can be resisted, considering both efficiency of public transit and experience of passengers. The stop-skipping can be activated with higher threshold value.

According to the dynamic control means selection procedure, the bus at the CPC can make proper decision to equalize the two successive bus headways. The bus headways on the whole route can be regulated by continually equalizing the successive bus headways.

2.3. Control Strategy for Bus at CPS. As mentioned in Section 2.1, the stop-skipping control means is a strong way to 

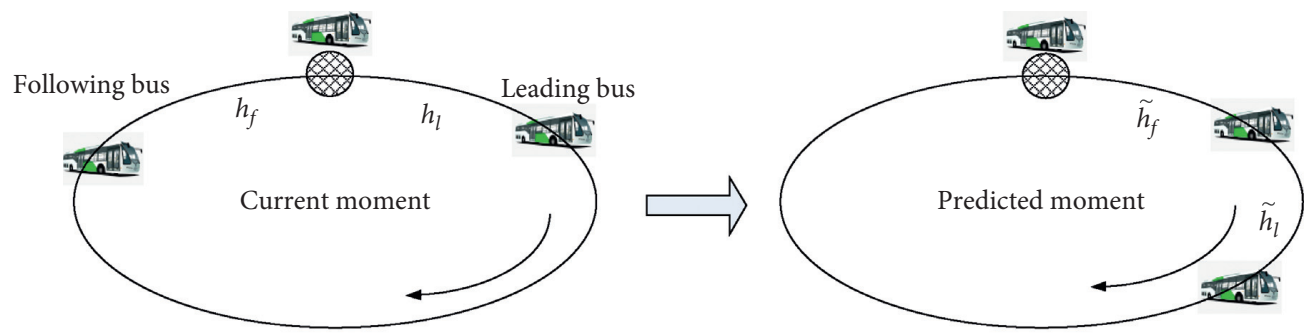

Control point

프매단 Bus

- Bus line

Figure 1: Prediction step length in the coordinated control method.

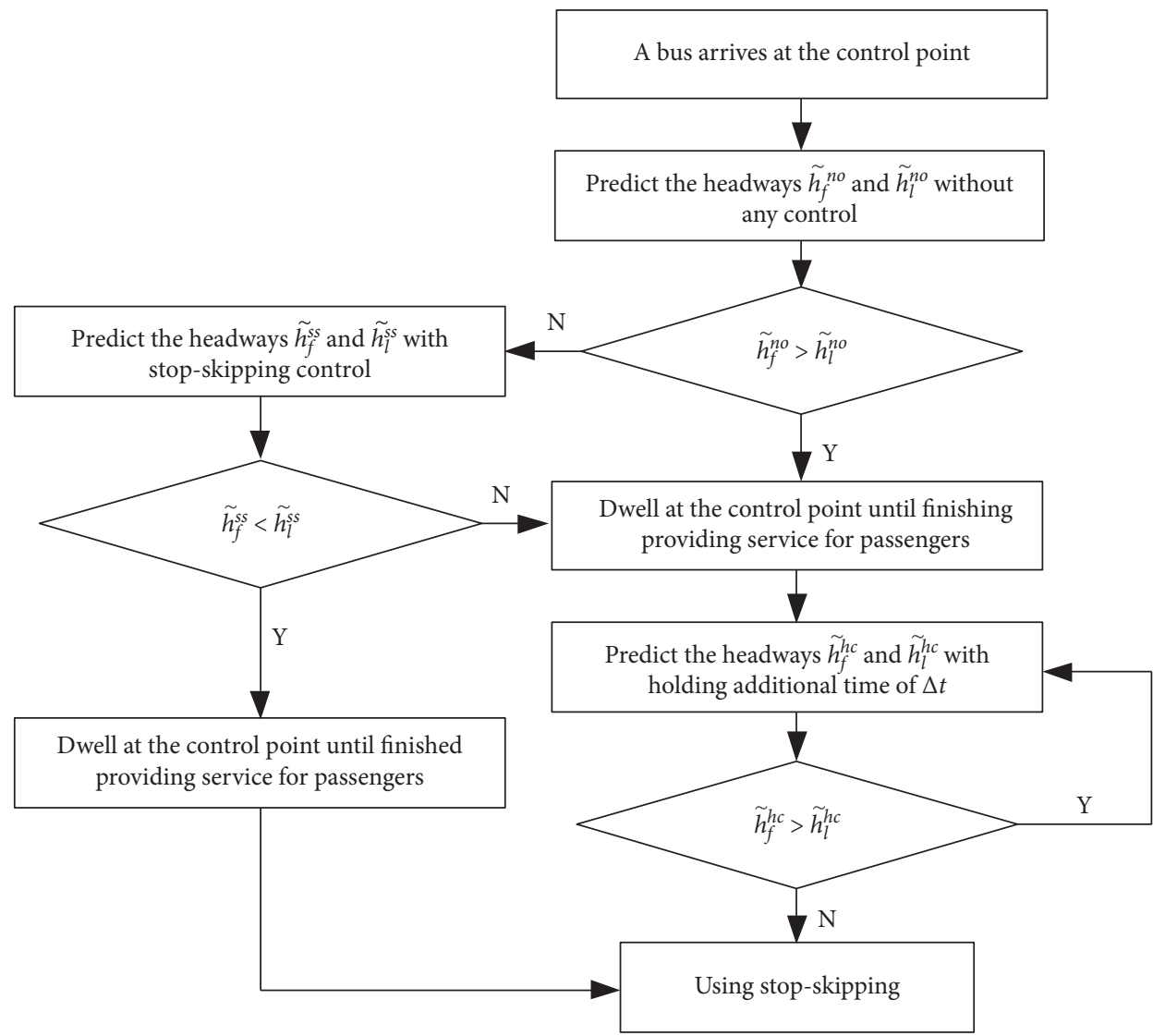

Figure 2: Control procedure for buses at CPC.

balance the bus headway. Meanwhile, stop-skipping control mean will provoke dissatisfaction of passengers waiting at the bus stop. At the CPS instead of CPC, this control means can be used according to the control concept shown in Figure 3.

\section{Bus Operation and Passengers' Evolution under Different Control Scenarios}

In this section, a second by second discrete system for description of bus operation process is formulated. On a bus line, the bus always runs on the road between two adjacent bus stops or dwells at the bus stop to provide service to the passengers. The bus stop can be classified into normal bus stop and control point.

3.1. Bus Operation at Normal Bus Stops for No Control. A discrete system is designed to describe the operation of buses. The running time is divided into a serious of uniform short time intervals $\Delta t$, e.g., 1 second.

A bus can move forward between two adjacent bus stops with distance $\Delta t \cdot v(t)$; we assume the velocity $v(t)$ of bus is constant during short time interval from $t$ to $t+\Delta t$. Therefore, the location $l_{n}(t+\Delta t)$ of bus $n$ at time $t+\Delta t$ on the bus line between two adjacent bus stops can be shown as 


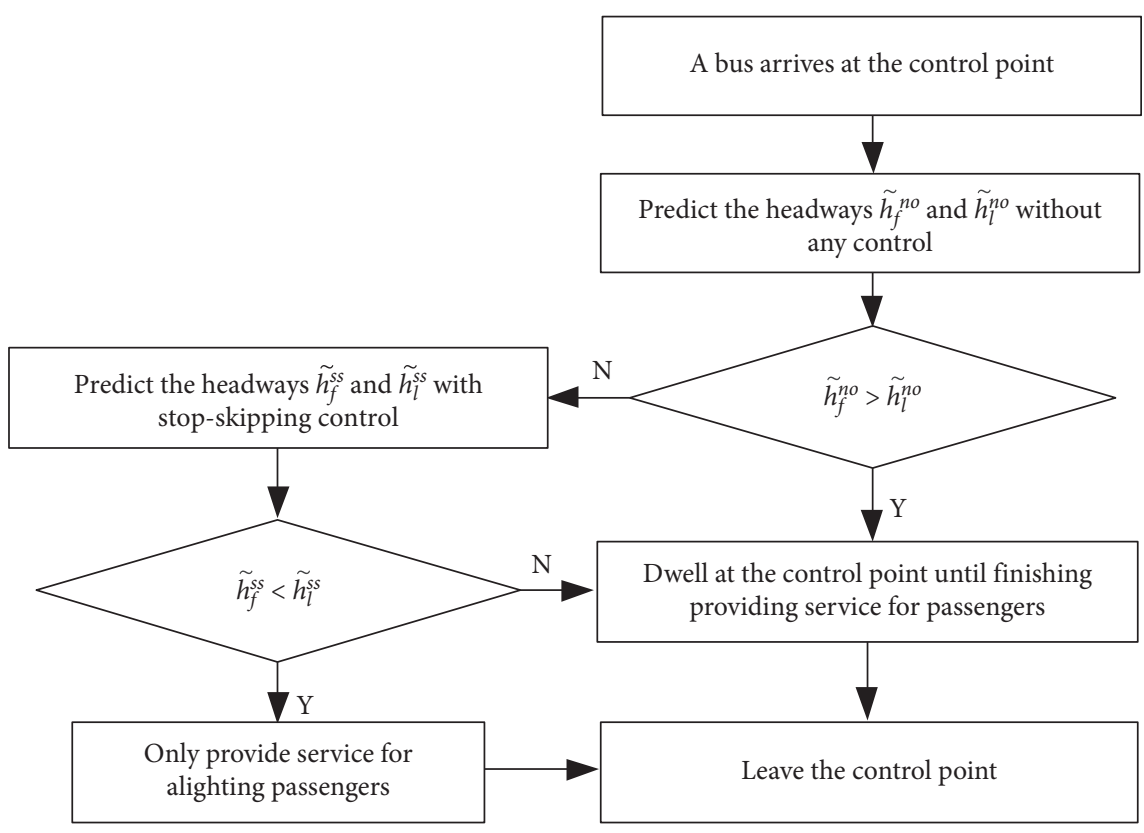

Figure 3: Principal control strategy procedure for buses at CPS.

$$
l_{n}(t+\Delta t)=l_{n}(t)+\Delta t \cdot v(t)
$$

If a bus $n$ encounters bus stop $s$, the passengers waiting at the bus stop $s$ begin to get on bus $n$. The criteria of bus $n$ arriving at bus stop $s$, whose location is expressed by $l_{s}$, can be written as

$$
l_{n}(t+\Delta t)-l_{s} \in[0, \Delta t \cdot v(t))
$$

The boarding time of one passenger is assumed constant, expressed by $\alpha$, and the alighting time of one passenger is constant as well, expressed by $\beta$. Therefore, the dwell time of one bus at bus stop for providing service to passengers can be written as

$$
t_{\mathrm{d}}=\max \left(\alpha \cdot P_{\mathrm{b}}, \beta \cdot P_{\mathrm{a}}\right)
$$

where $P_{\mathrm{b}}$ and $P_{\mathrm{a}}$ refer to the number of boarding and alighting passengers, respectively.

In the description system, the $P_{n}(t)$ represents number of passengers on the bus $n$ at time $t ; W_{s}(t)$ refers to number of passengers waiting at the bus stop $s$ at time $t ; A_{s}(t)$ means number of passengers that newly arrived at bus stop $s$ during the period from $t$ to $t+\Delta t$. In one time interval $\Delta t$, the process of alighting and boarding can be expressed by

$$
\left\{\begin{array}{l}
P_{n}(t+\Delta t)=P_{n}(t)+\frac{\Delta t}{\alpha}-\frac{\Delta t}{\beta}, \\
W_{\mathrm{s}}(t+\Delta t)=W_{\mathrm{s}}(t)+A_{\mathrm{s}}(t)-\frac{\Delta t}{\alpha} .
\end{array}\right.
$$

In fact, equation (4) only gives description of alighting and boarding process without considering bus capacity limit. If the bus capacity $C$ is considered, equation (4) is only suitable to be used when $P_{n}(t)+(\Delta t / \alpha)-(\Delta t / \beta)$ is not larger than the $C$. Otherwise, the passengers cannot get on the bus because of capacity limit, although there still are passengers on the bus stop $s$. Therefore, the passengers at the bus stop cannot get on bus $n$. The alighting and boarding process for passengers can be expressed by

$$
\left\{\begin{array}{l}
P_{n}(t+\Delta t)=P_{n}(t)-\frac{\Delta t}{\beta} \\
W_{s}(t+\Delta t)=W_{s}(t)+A_{s}(t) .
\end{array}\right.
$$

If the total number of alighting passengers $\sum \Delta t / \beta$ during dwell time has been equal to $P_{\mathrm{a}}$, the part $\Delta t / \beta$ in line one of equations (4) and (5) should be deleted.

The bus $n$ cannot leave bus stop $s$ until meeting one of following two constraint conditions:

$$
\left\{\begin{array}{l}
W_{s}(t)=0, \quad P_{\mathrm{a}}=\sum \frac{\Delta t}{\beta}, \\
P_{n}(t)=C, \quad P_{\mathrm{a}}=\sum \frac{\Delta t}{\beta} .
\end{array}\right.
$$

3.2. Bus Operation at CPS. If bus $n$ has determined to skip bus stop $s$, the bus still should dwell at the bus stop $s$ to provide service for the alighting passengers, if any. Therefore, the location of bus is the same as the bus stop, $l_{s}$.

$$
l_{n}(t+\Delta t)=l_{s}
$$

Meanwhile, the passengers on bus who would like to alight can get off, while the passengers waiting at the bus stop cannot get on the bus. Therefore, the bus cannot leave the bus stop until all the passengers who would like to get off have finished. The process of alighting and the number of passengers waiting at bus stop $s$ can be expressed by 


$$
\left\{\begin{array}{l}
P_{n}(t+\Delta t)=P_{n}(t)-\frac{\Delta t}{\beta}, \\
W_{s}(t+\Delta t)=W_{s}(t)+A_{s}(t) .
\end{array}\right.
$$

When the stop-skipping control means is used, the capacity of bus should not be considered as constraint. The bus can leave the CPS when all the passengers wanting to alight at the bus stops have finished, which can be written as

$$
P_{\mathrm{a}}=\sum \frac{\Delta t}{\beta} .
$$

After providing service for the alighting passengers, the bus can leave the bus stop, and the location evolution of bus can be written as

$$
l_{n}(t+\Delta t)=l_{s}+\Delta t \cdot v(t)
$$

3.3. Bus Operation at CPC. If the encountered bus stop is a $\mathrm{CPC}$, the bus can leave the CPC when all the passengers wanting to alight at the bus stop $s$ have finished, which can be written as equation (9).

If the stop-skipping control means is abandoned, the bus can provide service for passengers at the CPC. The evolution of passengers on bus and the CPC is same as equations (4) and (5). When the bus has finished the normal service for alighting and boarding passengers, it should consider whether the bus holding control means should be used or not. As mentioned in Section 2, the passengers that newly arrived at the CPC can still get on the holding bus. Therefore, the boarding process and the passengers' number during the holding time can be expressed by

$$
\left\{\begin{array}{l}
P_{n}(t+\Delta t)=P_{n}(t)+\frac{\Delta t}{\alpha}, \\
W_{s}(t+\Delta t)=W_{s}(t)+A_{s}(t)-\frac{\Delta t}{\alpha} .
\end{array}\right.
$$

The bus can leave the CPC when the predicted bus headway $\widetilde{h}_{f}^{\text {hc }}$ is no larger than $\widetilde{h}_{l}^{\text {hc }}$, and all the newly arrived passengers have boarded the bus. The condition should meet

$$
\left\{\begin{array}{l}
W_{s}(t)=0 \\
\tilde{h}_{f}^{\mathrm{hc}} \leq \tilde{h}_{l}^{\mathrm{hc}}
\end{array}\right.
$$

If the number of passengers on the bus has reached the capacity of the bus, the passengers cannot get on the bus any longer. Therefore, if the bus is full, the passenger evolution during holding time can be written as

$$
\left\{\begin{array}{l}
P_{n}(t+\Delta t)=P_{n}(t), \\
W_{s}(t+\Delta t)=W_{s}(t)+A_{s}(t) .
\end{array}\right.
$$

The bus can leave the CPC when the condition shown in equation (14) is achieved:

$$
\tilde{h}_{f}^{\mathrm{hc}} \leq \tilde{h}_{l}^{\mathrm{hc}} .
$$

\section{Performance Index for Headways and Travel Time of Passengers}

4.1. Total Travel Time of Passengers' Calculation Model. In this paper, the bus operation process and the passengers' arrival process are described as a discrete system. The number of passengers at the bus stops may not be integer in every time. Therefore, only integer part of the passengers at the bus stops should be added up.

Therefore, the total waiting time $T_{w}$ at the bus stops can be calculated by the formula written as

$$
T_{w}=\Delta t \cdot \sum_{t=o}^{T} \sum_{s=1}^{S}\left\lceil W_{s}(t)\right\rceil .
$$

In equation (15), the $\left[W_{s}(t)\right]$ means the integer part of passengers' number at the bus stops, and the $T$ means the end of implement time of $t$. Adding up all the passengers at bus stops at each time $t$ and multiplying time interval $\Delta t$, the total waiting time for passengers at the bus stops can be obtained.

The number of passengers on buses is not always an integer, because the operation of buses and passengers' description system are discrete. When the bus dwells at the bus stop, the passenger may not finish the boarding process in one interval $\Delta t$. Therefore, the travel time of passengers on buses cannot be the summation of passengers' number in every interval $\Delta t$. In addition, the waiting time at the bus stops adds up all the integer part, so that the decimal part should be counted into the travel time on buses. Therefore, the total travel time $T_{p}$ on buses can be calculated by

$$
T_{p}=\Delta t \cdot \sum_{t=o}^{T} \sum_{n=1}^{N}\left\lfloor P_{n}(t)\right\rfloor .
$$

In equation (17), $N$ refers to the total number of buses running on the bus route, and $\left\lfloor P_{n}(t)\right\rfloor$ means the passengers on buses rounding up to an integer. Therefore, adding up all the passengers on every bus during all the time and multiplying the time interval $\Delta t$ can obtain the total travel time of passengers on buses. Therefore, the total travel time TT for passengers including the waiting time at bus stops and travel time on buses can be written as

$$
\mathrm{TT}=T_{w}+T_{p} .
$$

4.2. Bus Headways Calculation Model. The other index reflecting the performance of public transit is the bus headway. In the transit corridor, the bus operation pays more attention on the deviation of bus headways instead of a schedule. Because the average bus headways value is relatively small (about $3 \mathrm{~min}$ to $5 \mathrm{~min}$ ), the bus headways are expected to be equalized with each other.

In this paper, the bus headway is defined as the time between two successive buses leaving the same bus stop. Therefore, the bus headway at the bus stop $s$ can be expressed by 


$$
H_{s}= \begin{cases}t_{n+1, s}-t_{n, s}, & \text { if } n<N, \\ t_{1, s}-t_{n, s}, & \text { if } n=N .\end{cases}
$$

In equation (18), $t_{n, s}$ means the time bus $n$ leaving bus stop $s$. The bus $n$ is the leading bus, followed by bus $n+1$. Therefore, the bus headway should be $t_{n+1, s}-t_{n, s}$. It should be mentioned that if the value of $n$ is equal with the total number of buses on the route $N, n+1$ is not meaningful. According to the actual physical meaning, the bus $N+1$ should be bus 1 . The standard deviation of bus headways can be expressed by

$$
\sigma_{s}=\sqrt{\frac{1}{N_{n}-1} \sum_{1}^{N_{n}-1} H_{s} .}
$$

In equation (19), $N_{n}$ means the times buses passed the bus stop, so that the number of bus headways is $N_{n}-1$.

Therefore, the index values of travel time of passengers and bus headways can be calculated by the equations formulated in this section.

\section{Numerical Analysis}

In this section, numerical tests are conducted to analyze the performance under variable CPS selected. In Section 5.1, the input data for the bus route is introduced including the arrival process of passengers at bus stops and the distribution of bus stops on the bus line. In Section 5.2, the test results under variable distribution of CPS are presented with index of performance mentioned in Section 4. Finally, the result analysis is conducted and several conclusions and suggestions about the setting of CPS are obtained.

5.1. Input Data of the Bus Route. The length of the simulation bus route is $12 \mathrm{~km}$, with 15 bus stops on the bus route. Average distance between two adjacent bus stops is $0.8 \mathrm{~km}$. There are 11 buses running on the bus route whose capacity is 100 pax. The average travel speed between two successive bus stops is $5 \mathrm{~m} / \mathrm{s}$. Considering the random disturbance caused by passengers' arrival process, the travel speed of buses on the bus route is stochastic, because of random dwell time at bus stops. The simulation time in one test is $4 \mathrm{~h}$. To evaluate the performance of the proposed control method under high traffic demands, the average arrival rate of the bus route is $2970 \mathrm{pax} / \mathrm{h}$, and the distributions at the bus stops are same. The alighting proportions at each bus stop are shown in Figure 4. Since the arriving process is stochastic, special cases may occur. According to the Monte Carlo method, repeating the tests for enough times can obtain a more general conclusion. Therefore, to eliminate effects of random factors, the program was run 100 times to generate passenger arrival processes at bus stops. We built a simulation platform based on the running process of buses described in Section 3 and imbedded the control method into it. In Figure 5, the relationship between simulation times and the convergence tendency of performance indices is presented, illustrating that repeating 100 times is enough.

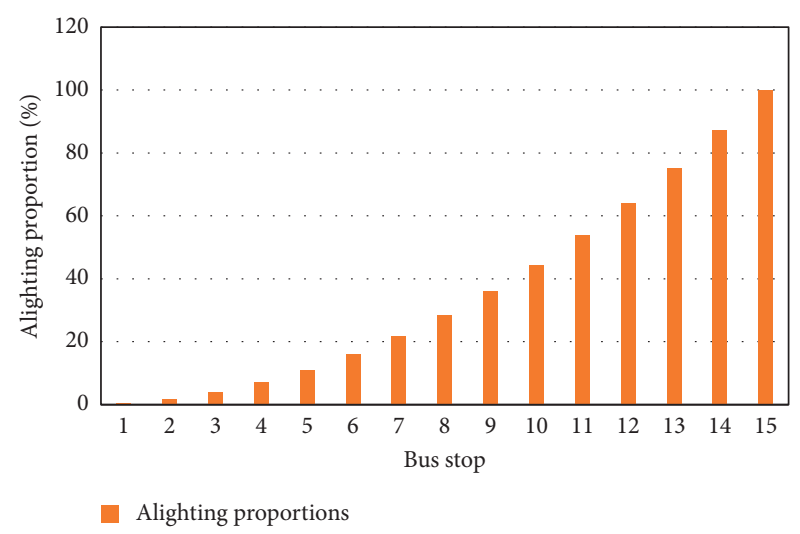

FIGURE 4: Percentage of average passenger alighting at each stop.

There are two $\mathrm{CPH}$ which are fixed at bus stop 6 and bus stop 11, while the variable setting of CPS is shown in Table 1.

As shown in Table 1, 10 groups are set to select variable locations of CPS. Among them, S1 and S2 have only one CPS where the bus stop 6 locates at the beginning section of bus route, while bus stop 11 locates at the end section of bus route. In group $\mathrm{S} 3$, the two $\mathrm{CPS}$ are same with $\mathrm{CPH}$. The groups S4 and S5 have three CPS while the groups S6, S7, S8, and $S 9$ have four CPS, and their spatial distributions are different. Group S10 have the most CPS with five.

\subsection{Test Results under Variable Number and Location of CPS.} In this section, the raw test results are presented first to give preliminary impression of bus operation under different number of CPS. More detailed indices and insight can be seen in Section 5.3.

Firstly, the trajectories of buses in groups S1, S3, S4, S7, and S10 are presented in Figure 6, where the five groups mean different number of CPS from 1 to 5 . According to Figures 6(a) and 6(b), the bus operation is not quite regular as several buses tend to be very close to each other. In addition, the bus holding time at the two $\mathrm{CPH}$, at $4 \mathrm{~km}$ and $8 \mathrm{~km}$, is relatively long. According to Figures 6(c)-6(e), the trajectories of buses are smoother than those in the first two figures, in which the bus headways are more equalized with each other. It is obvious that the holding time at the two $\mathrm{CPH}$ is shorter than that in the first two figures as well. However, the bus headway cannot be more regular when the number of CPS is relatively large, because the situations presented in the last three figures are quite same.

Figure 7 shows the passengers on buses when the bus just left the bus stop under different number of CPS with five groups. According to Figure 7, the number of passengers grows gradually along with the buses running on the bus route, reaching peak values at bus stop 5 to bus stop 8 and then decreases gradually at the end section of the bus route. In more detail, the situations of passengers on buses presented in Figures 7(a) and 7(b) illustrate that the passengers on buses at bus stop 5 fluctuate greatly. The maximum values of passengers on buses at bus stop 4 to bus stop 7 reach the capacity of the bus 100 pax, while the minimum values are 


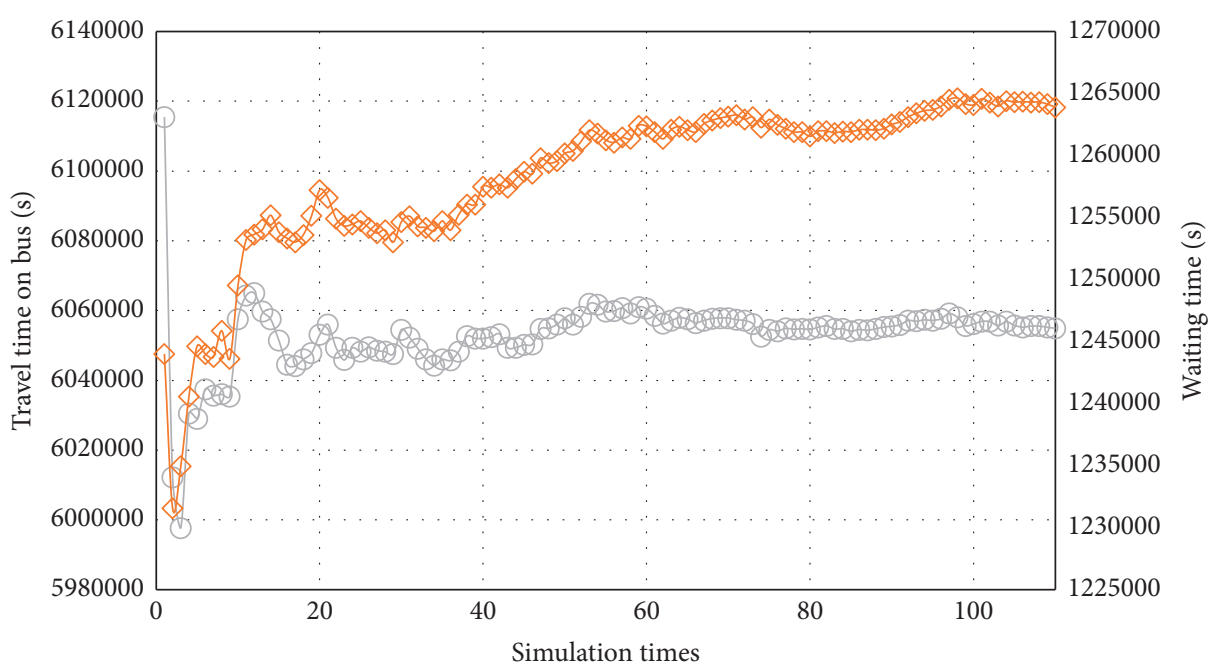

(a)

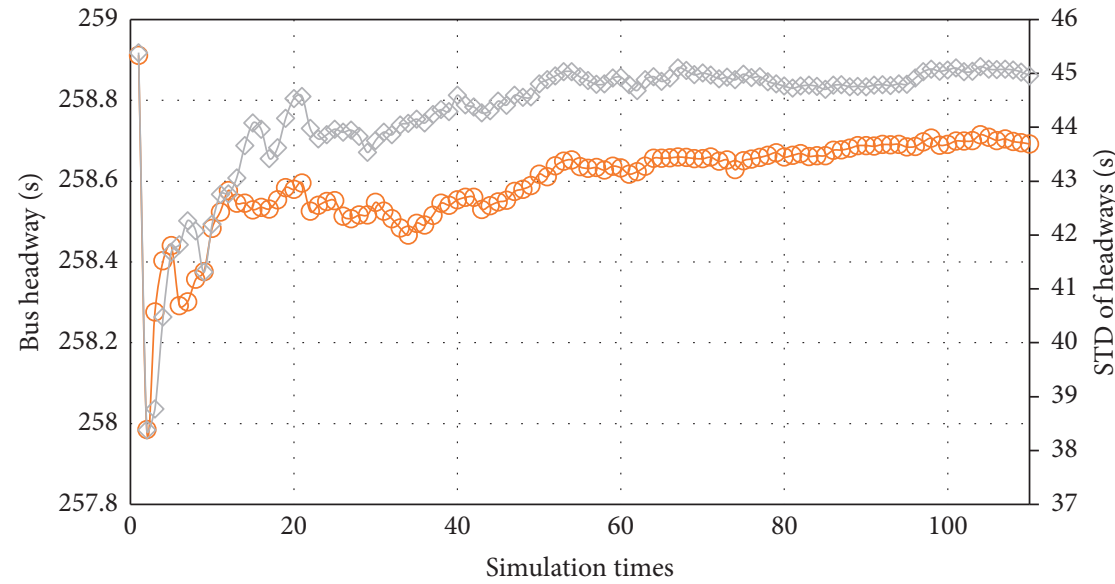

(b)

Figure 5: The convergent tendency with increasing of simulation times. (a) Travel time on bus and waiting time at bus stops. (b) Bus headways and STD of bus headways.

TABLE 1: Bus stops selected for stop-skipping.

\begin{tabular}{lc}
\hline Group & Location of CPS \\
\hline S1 & 6 \\
S2 & 11 \\
S3 & 6,11 \\
S4 & $3,6,11$ \\
S5 & $6,9,11$ \\
S6 & $6,11,14$ \\
S7 & $2,4,6,11$ \\
S8 & $6,8,10,11$ \\
S9 & $6,11,13,15$ \\
S10 & $3,5,8,10,13$ \\
\hline
\end{tabular}

quite small. It means the capacity of some buses is not fully used while the other buses are quite crowded. This phenomenon has been greatly improved in Figures $7(\mathrm{c})-7(\mathrm{e})$, where the fluctuating range of passengers on buses is relatively small, which means the capacity of buses fully used.

Similar to the conclusion obtained from Figure 6, the passengers on the bus feel more comfortable along with the increasing of CPS number, because the numbers of passengers in different buses at the same bus stop become more equalized. However, the brought benefits become inconspicuous when the number of CPS is large enough.

According to the intuitionistic raw test results, a preliminary conclusion can be achieved; the bus headway can be equalized and the bus operation process can be regulated along with the increasing of CPS number. However, the benefits will not increase persistently, especially when the number of CPS is relatively large. Therefore, the relationship between the location distribution of the CPS and the performance of the control method should be explored further. 


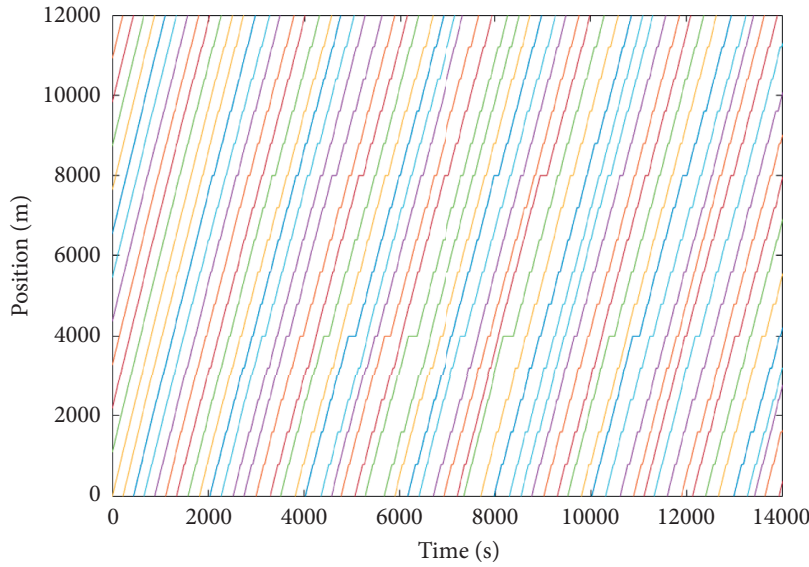

(a)

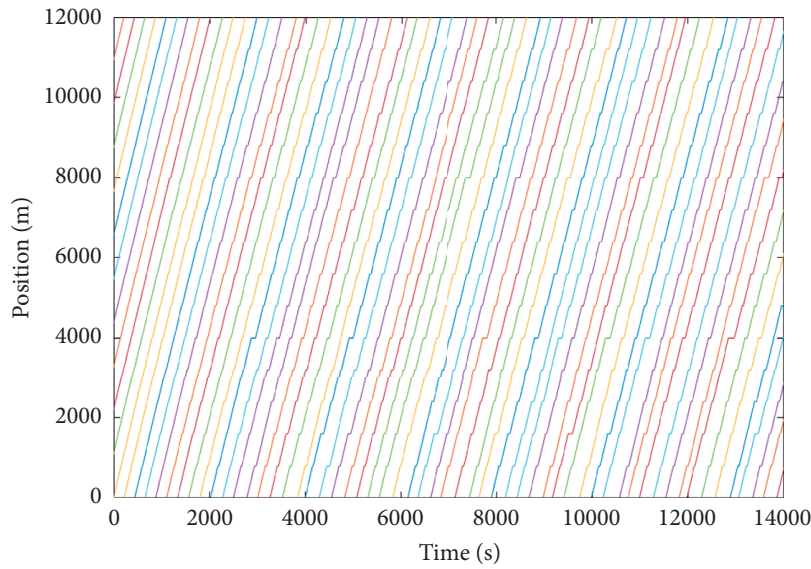

(c)

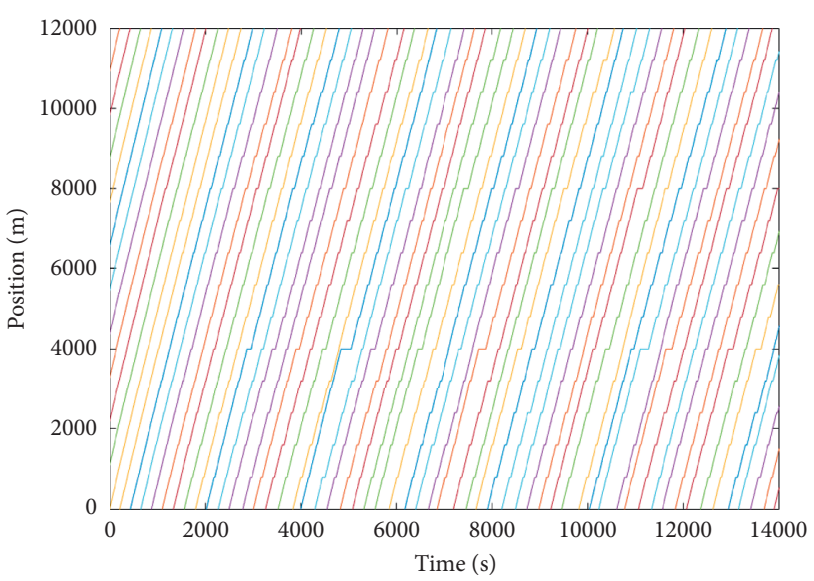

(b)

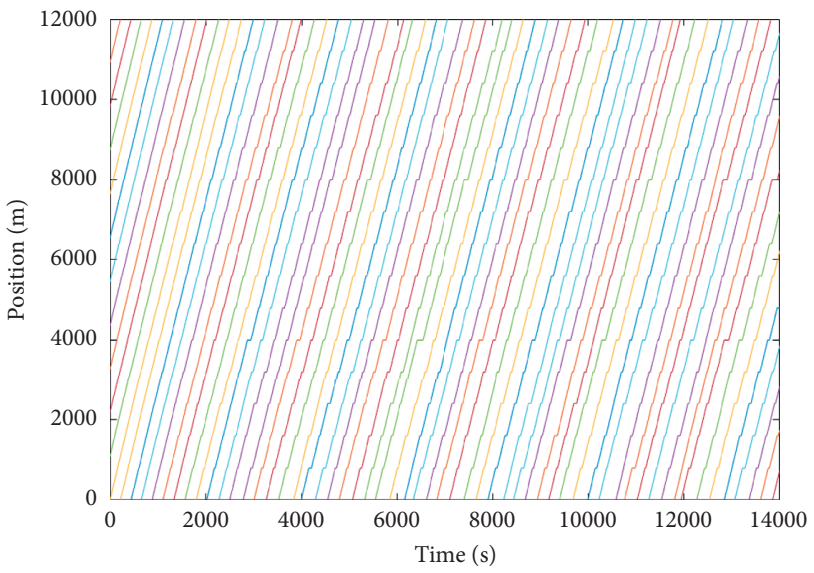

(d)

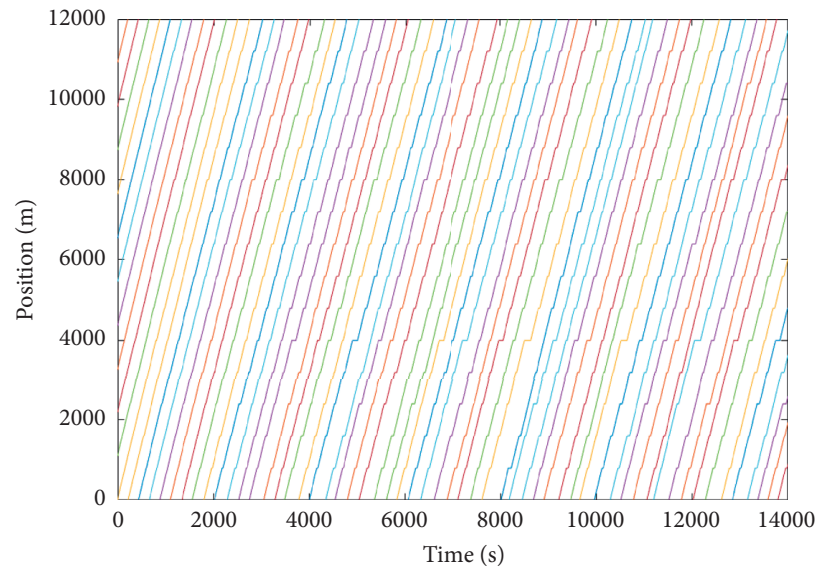

(e)

FIGURE 6: The trajectories of buses under different number of CPS. (a) S1. (b) S3. (c) S4. (d) S7. (e) S10.

5.3. Results Analysis under Variable Number and Distribution of CPS. In this section, the indices of the control method performance are presented including bus operation and the experience of passengers. The relationship between the performance of the control method and the number and distribution of CPS is presented followed by the explanation for these phenomena. Furthermore, several conclusions and suggestions are proposed for application in practice.
Because the passengers' arriving process is stochastic, only one simulation and test cannot obtain an impartial result. Therefore, we conduct many times simulations and tests and obtain an average result to reflect the true performance of the control method. However, the times should be discussed. More simulations can obtain more impartial result, while too many simulations may lead to waste of time. Therefore, we should obtain the convergence process along 


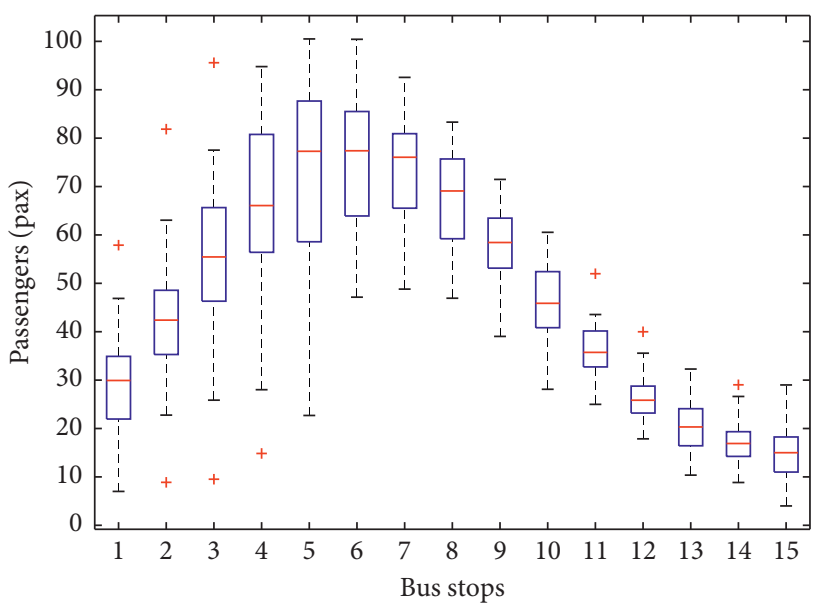

(a)

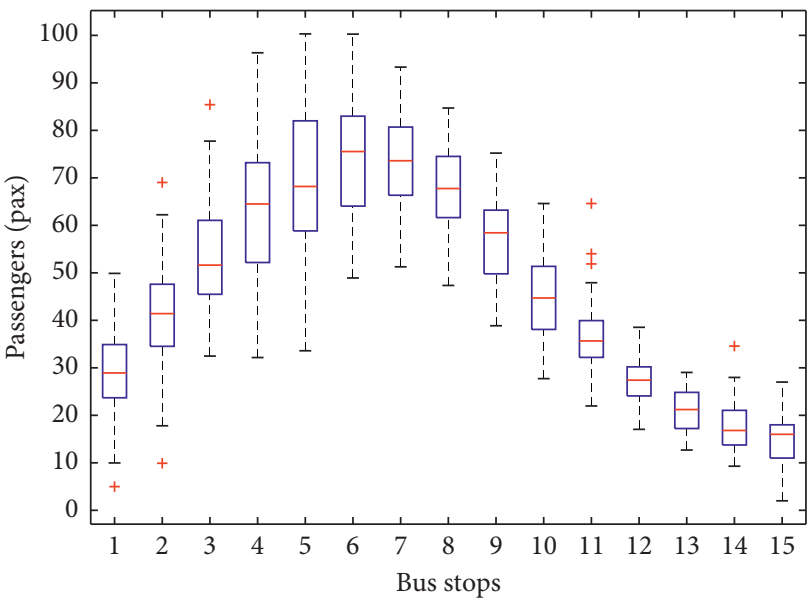

(c)

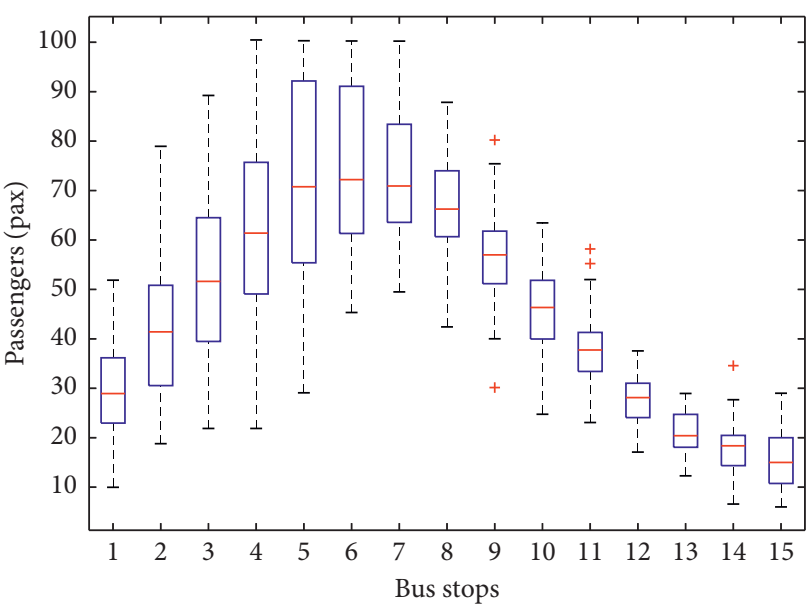

(b)

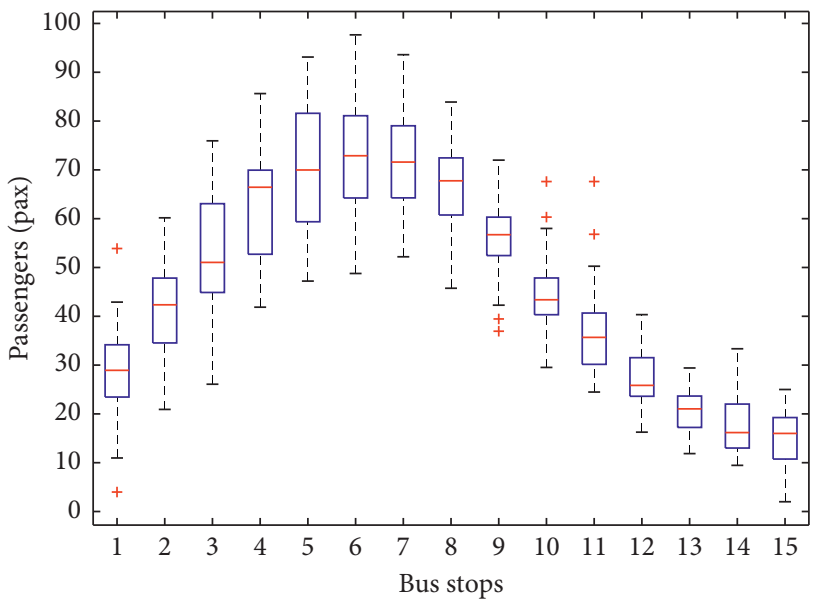

(d)

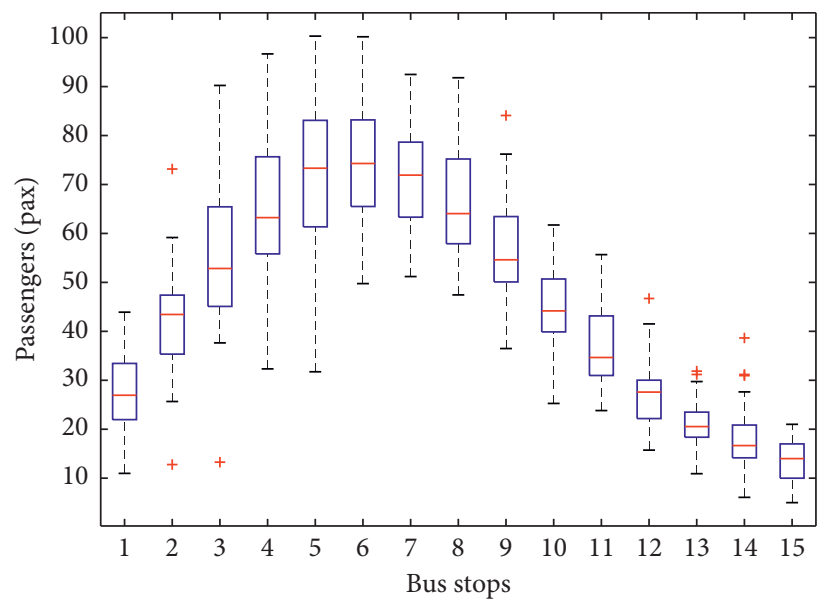

(e)

Figure 7: The passengers on buses under different number of CPS. (a) S1. (b) S3. (c) S4. (d) S7. (e) S10.

with the increasing of simulation times. Figure 5 shows that the performance result can be convergent, when the simulation repeated for 100 times. In this section, each test group has been repeated for 100 times. The relationship between average values of main indices and the simulation times is presented in Figure 7. According to this figure, it is obvious that the values tend to stablize and fluctuate a little. Therefore, the 100 times simulation can represent a general result for one fixed setting.

The indices values extracted from the test results are presented in Table 2, involving the total travel time, total waiting time, travel time on bus, average bus headway, STD 
TABLE 2: The performance indices under variable number of CPS.

\begin{tabular}{|c|c|c|c|c|c|c|}
\hline Group & Total travel time $(\mathrm{s})$ & Total waiting time & Time on bus (s) & Average headway (s) & STD of headway (s) & Skipping times \\
\hline S1 & 7310775 & 1252021 & 6058754 & 260.91 & 60.10 & 10.68 \\
\hline S2 & 7300540 & 1257292 & 6043249 & 261.53 & 63.14 & 5.71 \\
\hline S3 & 7341375 & 1261543 & 6079832 & 260.54 & 59.32 & 15.20 \\
\hline S4 & 7285720 & 1256509 & 6029211 & 259.03 & 48.16 & 21.81 \\
\hline S5 & 7351393 & 1261139 & 6090254 & 260.16 & 57.60 & 17.70 \\
\hline S6 & 7342283 & 1261077 & 6081206 & 260.10 & 56.35 & 18.27 \\
\hline S7 & 7267743 & 1256691 & 6011052 & 258.51 & 42.55 & 24.45 \\
\hline S8 & 7331101 & 1253641 & 6077460 & 259.86 & 55.95 & 18.13 \\
\hline S9 & 7375701 & 1245524 & 6130177 & 259.55 & 49.74 & 18.50 \\
\hline S10 & 7318832 & 1263890 & 6054942 & 258.69 & 44.96 & 25.38 \\
\hline
\end{tabular}

of headway, and skipping times. The first three indices in Table 2 can reflect the travel time cost including at bus stops and on buses. The middle two indices average bus headways and STD of headways reflect the operating efficiency and the reliability of public transit, respectively. The last column means skipping times occurred at the CPS. According to the raw values shown in Table 2, the performance of the control method will not become monotone better along with the increasing of number of CPS. Therefore, in order to reflect both distribution and the number of CPS influence on the performance of the control method, more detailed comparisons are shown in Tables 3-6. The classification of the ten groups is shown in Table 7. For example, the group S1 has one CPS which locates at the front (head) section of the bus route, so that $\mathrm{S} 1$ locates at the first line and first column in Table 7. In addition, the group S3 is set as the normal control group, which has two CPS at bus stop 6 and bus stop 11. The relative difference can be calculated by $S 3$ minus $S_{i}$ and divided by S3. Therefore, if the values of the relative difference indices are positive, it means the value of $S_{3}$ is larger. Otherwise, the values of performance indices of the S3 are smaller.

As shown in Table 3, the values of total travel time in S1, S4, and S7 are smaller than that in S3, which means the CPS locating at the front section of the bus route is beneficial to reduce the total travel time for passengers. In addition, the saved travel time increased from $0.42 \%$ to $1.00 \%$ along with increasing of CPS number. The increasing tendency also occurred when the CPS are set at the middle section of the bus route, shown in the second line of Table 3. However, the improvement values are lower than those in line one of Table 3 where the CPS locate at the front of the bus route. On the contrary, the improvement values of travel time decreased along with the increasing of CPS number when the CPS locate at the rear of the bus route. The reasons will be given in detail in the following content. As shown in Tables 4 and 5, both the headways and their STD decreased along with the increasing of CPS number, which means the operation efficiency and the regularity improved. The shorter bus headway and more regular bus headway mean that the passengers have less waiting time. Because the number of the buses is fixed on the bus line, the shorter bus headways also mean faster travel speed for buses and shorter travel time for passengers. However, the total travel time does not always decrease along with the increasing of CPS number. The
TABle 3: Travel time relative difference compared with group S2.

\begin{tabular}{lcccc}
\hline Travel time & 1 & 3 & 4 & 5 \\
\hline Front (\%) & 0.42 & 0.76 & 1.00 & - \\
Middle (\%) & - & -0.14 & 0.14 & 0.31 \\
Behind (\%) & 0.56 & -0.01 & -0.47 & - \\
\hline
\end{tabular}

TABLE 4: Bus headways relative difference compared with group S2.

\begin{tabular}{lcccc}
\hline Bus headways & 1 & 3 & 4 & 5 \\
\hline Front (\%) & -0.14 & 0.58 & 0.78 & - \\
Middle (\%) & - & 0.15 & 0.26 & 0.71 \\
Behind (\%) & -0.38 & 0.17 & 0.38 & - \\
\hline
\end{tabular}

TABLE 5: STD of bus headways relative difference compared with group S2.

\begin{tabular}{lcccc}
\hline STD of headways & 1 & 3 & 4 & 5 \\
\hline Front (\%) & -1.32 & 18.81 & 28.27 & - \\
Middle (\%) & - & 2.91 & 5.69 & 24.22 \\
Behind (\%) & -6.43 & 5.00 & 16.15 & - \\
\hline
\end{tabular}

difference of these two conclusions comes from the additional waiting time of passengers due to stop-skipping. According to Table 6, along with the increasing of CPS number, stop-skipping control means are applied more times to control the bus, and more passengers are denied to board. Therefore, if the benefits brought by the shorter and more regular bus headways cannot cover the negative influence by boarding limits, the performance of the control method will be bad and worse along with the increasing of CPS number. Combined with Table 3, if CPS locates at front or middle section of bus route, the total travel time will decrease along with increasing of stop-skipping times. However, if the CPS locates at the behind section of bus route, the total travel time will increase along with increasing of stop-skipping times, causing worse control result. Therefore, this means, in the framework of self-equalizing control concept, the distribution of the CPS has more influence on the performance of control method. In order to discover the total and distribution of waiting time for passengers, the box figures of passengers at each bus stop are presented in Figure 8. 
TABLE 6: Stop-skipping times relative difference compared with group S2.

\begin{tabular}{lcccc}
\hline Stop-skipping times & 1 & 3 & 4 & 5 \\
\hline Front (\%) & 29.75 & -43.45 & -60.83 & - \\
Middle (\%) & - & -16.43 & -19.27 & -66.96 \\
Behind (\%) & 62.43 & -20.15 & -21.70 & - \\
\hline
\end{tabular}

TABLE 7: Classification of CPS number and distribution.

\begin{tabular}{lcccc}
\hline Number of CPS & 1 & 3 & 4 & \\
\hline Front & S1 & S4 & S7 & \\
Middle & - & S5 & S8 & S10 \\
Behind & S2 & S6 & S9 & - \\
\hline
\end{tabular}

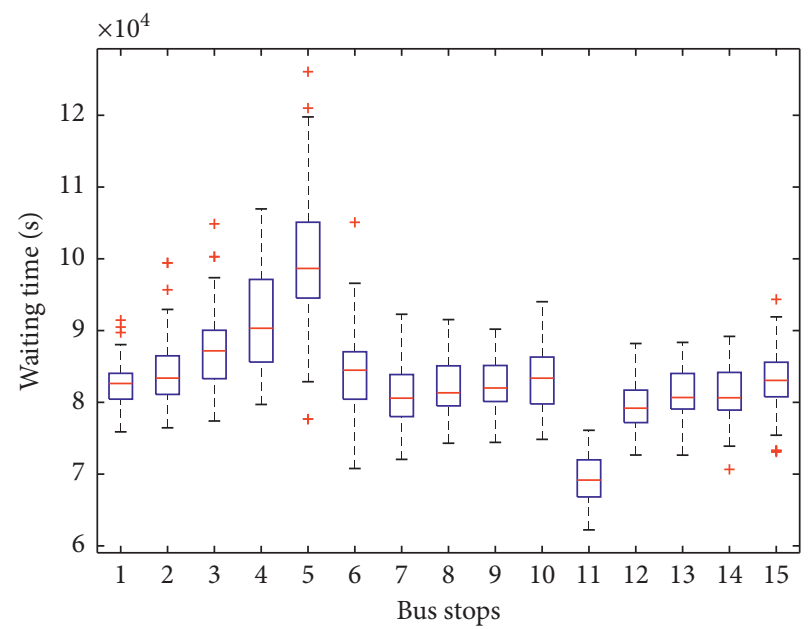

(a)

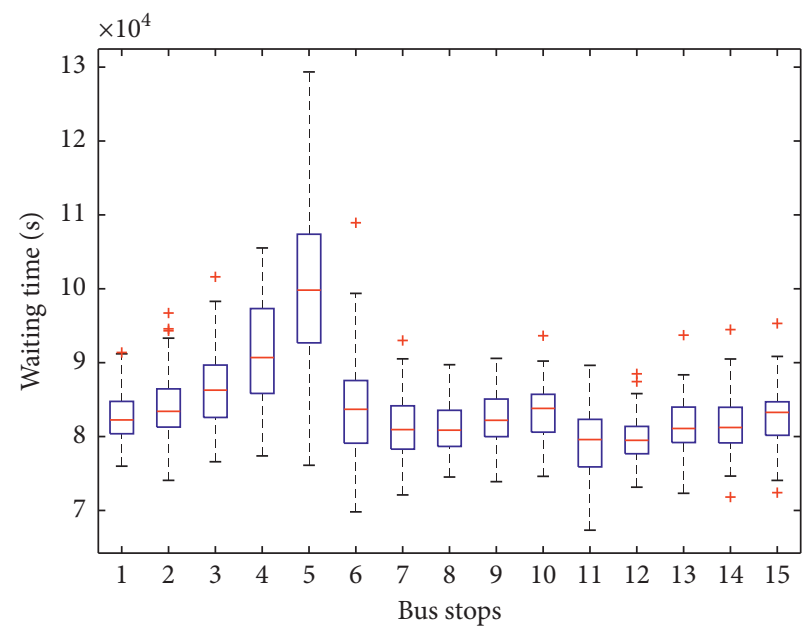

(c)

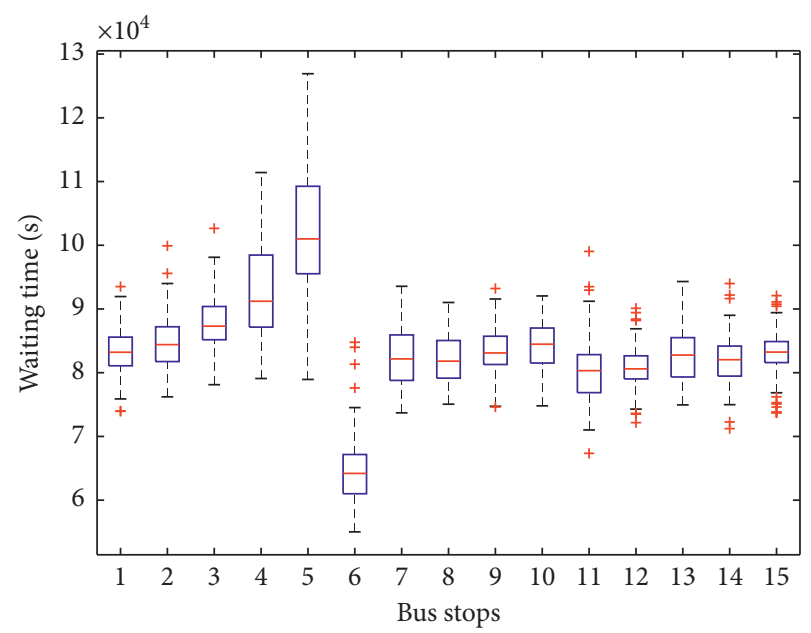

(b)

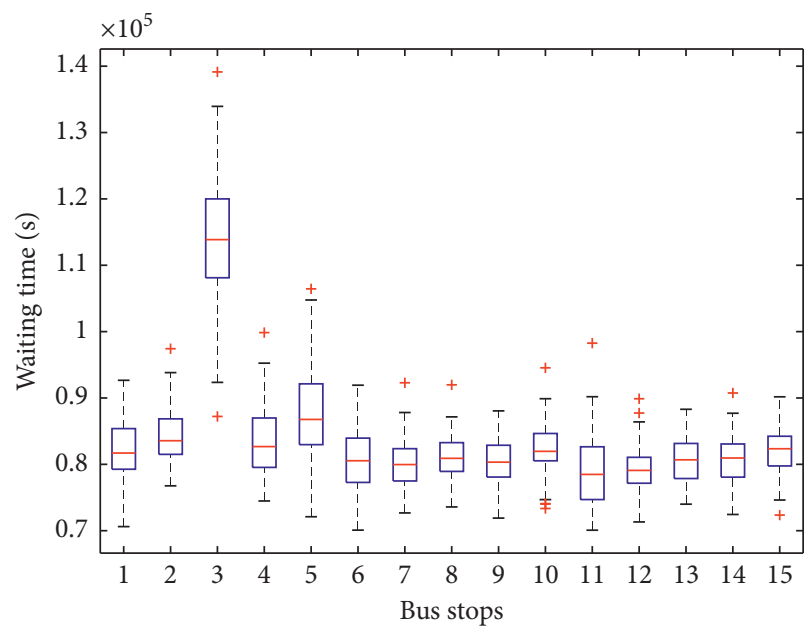

(d)

Figure 8: Continued. 


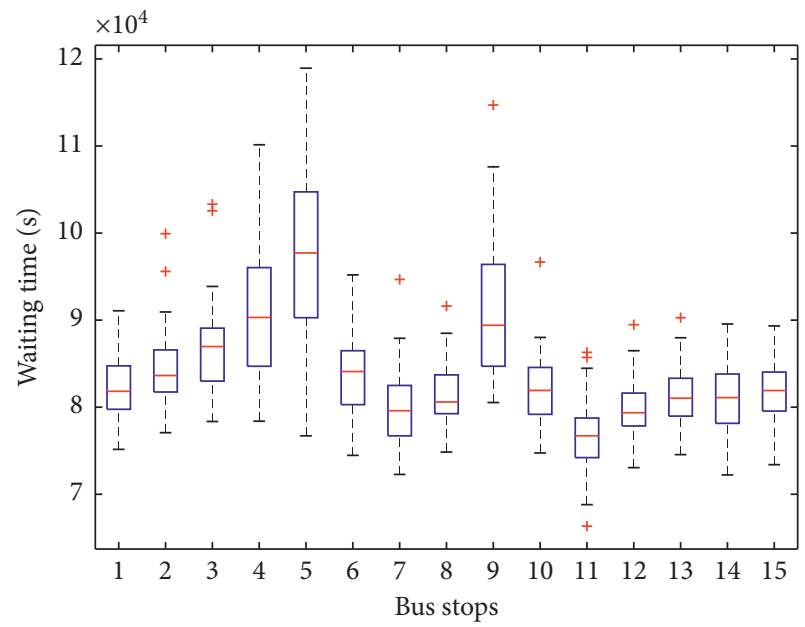

(e)

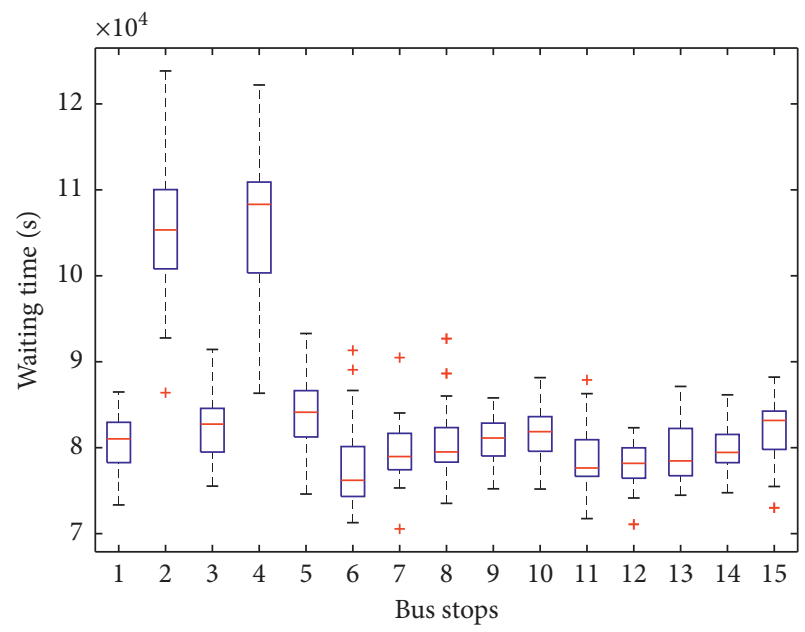

(g)

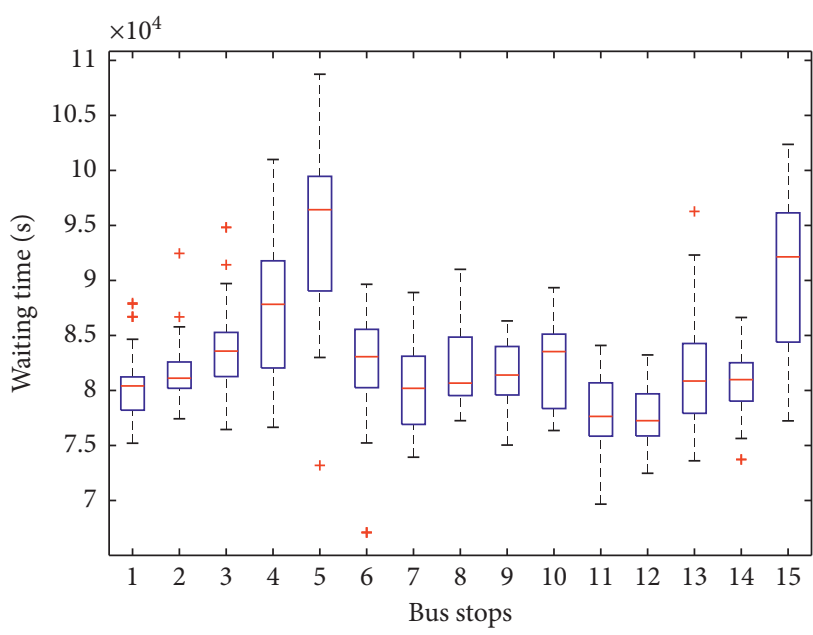

(i)

FIgURE 8: Waiting time of passengers at bus stops. (a) S1.

Figure 8(a) presents the waiting time of passengers at bus stops when the $\mathrm{CPH}$ locate at bus stop 6 and bus stop 11 , and the CPS locates at bus stop 6. At beginning of the five bus stops from 1 to 5 , the waiting time increased gradually; at bus

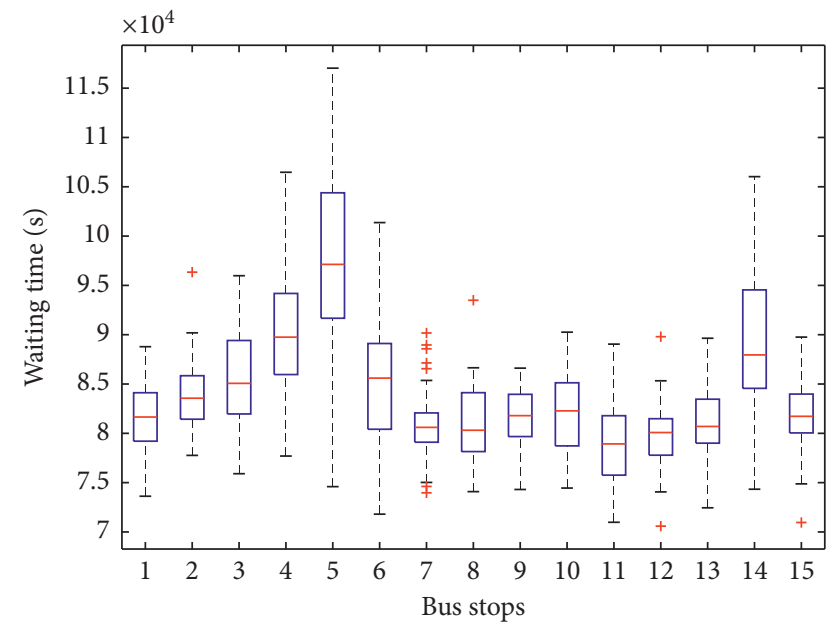

(f)

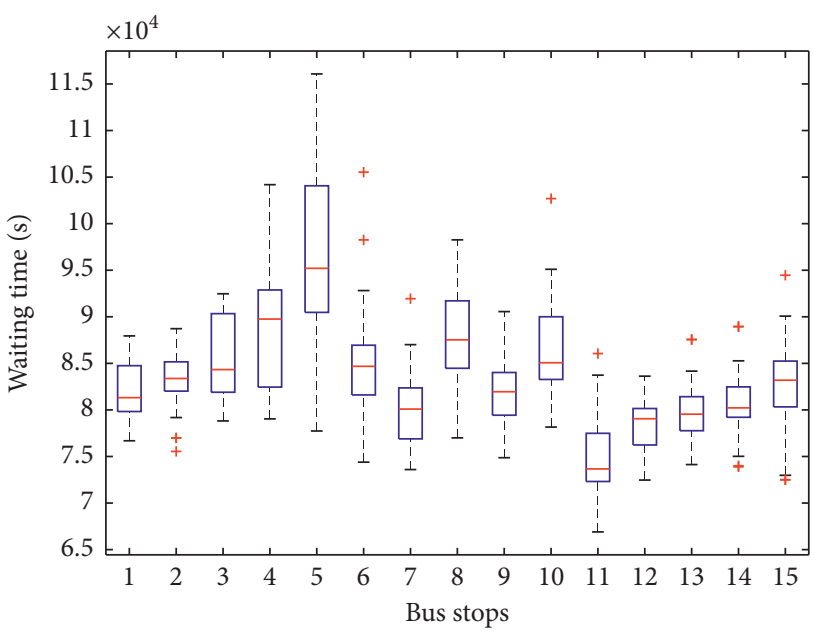

(h)

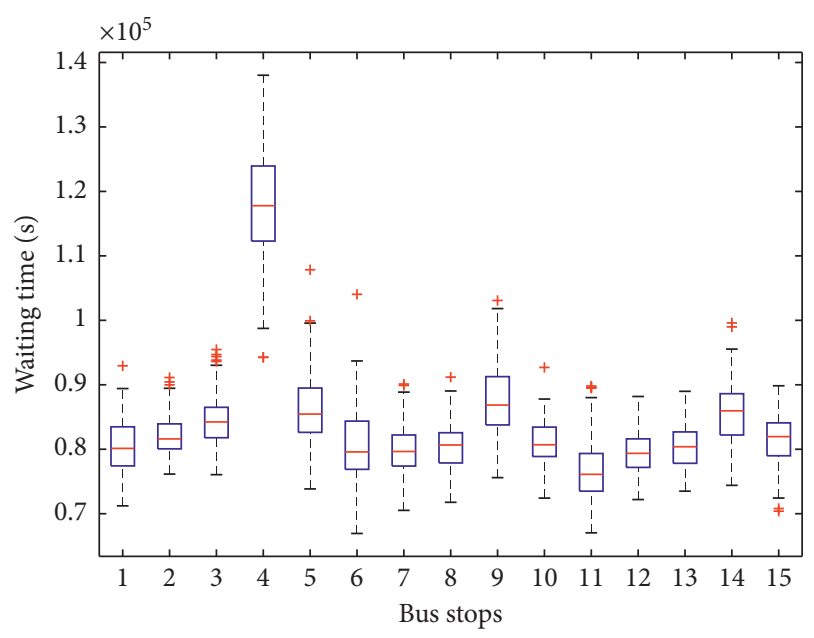

(j)

S2. (c) S3. (d) S4. (e) S5. (f) S6. (g) S7. (h) S8. (i) S9. (j) S10.

stop 5 the waiting time was the largest. The first reason is that the bus headways become more chaotic gradually when running at the bus route, and unequal bus headways lead to more waiting time. However, this is not the ultimate reason 
that the waiting time will not change so greatly if only affected by the unregular bus headways. The other important reason for large waiting time at bus stop 5 is that the passengers waiting at the bus stop cannot board because of capacity limit of the bus. According to Figure 7(a), the maximum number of passengers on bus has reached at the capacity of the bus (100 pax) while the minimum number of passengers on bus is only a little more than 20 pax. Therefore, in the group S1, the bus capacity is not well utilized, so some buses are relatively full while other are relatively empty because of unequal bus headways. Therefore, the bus headways should be equalized before the buses encounter busy section of the bus route where the buses are relatively full.

Therefore, the groups S1, S4, and S7 perform best because the bus headways are more equal before arriving at bus stop 5. Combining Figure $7(\mathrm{~d})$ with Figure $8(\mathrm{~g})$, the bus headways are quite equal before arriving at bus stop 5, and the number of passengers on each bus is relatively equal too. Therefore, the travel time on buses and the waiting time at bus stops of passengers are relatively small, and the total travel time is the smallest among these 10 groups.

The groups S5, S8, and S10 set the CPS at the bus stops of the middle bus line. Although the bus headway can be relatively equal at the busy section of bus route, the stop-skipping may lead to the resisted boarding passengers still not being able to board next arriving bus, because all the buses at the busy section are relatively full. In addition, the bunching tendency will be severe when the influence of initial disturbance is not eliminated timely. Therefore, the performance of control method in these group is worse than the "front groups."

The groups S2, S6, and S9 set the CPS at the bus stops of the bus line rear. The test results are worse than the "middle groups," because the bus headways are not equal when the buses arrived at bus stop 5. In addition, the stop-skipping control means increasing the waiting time of passengers. Therefore, the benefits brought by the equal bus headways are not large enough to cover the additional waiting time because of stop-skipping. The negative influence will be larger along with increasing of CPS number, while the equal bus headways are not benefit to the passengers most needed.

Therefore, several conclusions can be obtained according to the analysis mentioned above. The CPS should be located before the busy section of bus route, and the bus capacity can be fully utilized and avoid additional waiting time because of bus capacity limit. In addition, stop-skipping control means can equalize the bus headways and adjust the passengers on successive buses making the passengers on buses more equal. The CPS should be set at the bus stops where passengers' demand is relatively small, avoiding part of the passengers that cannot board next arriving bus again if the number of resisting passengers is relatively large and reducing the number of passengers who are unsatisfied because of stopskipping control means.

\section{Conclusion}

In this paper, the coordinated bus headway control method is designed based on the adaptive self-equalized concept. Furthermore, a procedure is designed to select the bus that should be skipping or held as well as its corresponding holding time. The discrete operation system is formulated, imbedding the coordinated control method, and considers the limitation of the bus capacity. However, the coordinated control method is not the core contribution of this paper. The main work of this paper is to discuss the setting of CPS to obtain better performance of the coordinated control method based on the selfequalizing bus headway control strategy. Therefore, four main indices are formulated including the waiting time of passengers at bus stops, the travel time on buses, the STD of bus headways, and the stop-skipping times.

In Numerical Analysis, a set of numerical tests is conducted under variable CPS settings. Ten groups are formulated representing different number and distribution of CPS. According to the test results of these 10 groups, several conclusions can be obtained. The control performance in groups S1, S4, and S7 is the best among these 10 groups, which means the CPS should be set at the beginning of the bus route, before the busy section of bus route, and the passengers on each bus are more equal, while less passengers are limited by the bus capacity. The increasing number of CPS will make the stop-skipping times larger, although the saved total travel times are larger as well. The distribution of the control points has larger influence on the performance of coordinated control method. If the distribution of the control points is not well set, a larger number of control points have more negative effects on the public transit in terms of total travel time of passengers. In addition, an extended conclusion can be obtained: the CPS is not suitable set at the large demand bus stops, because the rejected passengers, due to stop-skipping, may miss next arriving bus when there are relatively full passengers on bus and relatively large number of passengers at the bus stop. Therefore, the waiting time will increase and the passengers who resisted twice will be greatly unsatisfied.

Although this paper discussed the CPS setting to obtain better performance of the control method by a set of numerical analyses, the $\mathrm{CPH}$ settings are not considered, and deeper insight and theoretical proof are not given. More detailed and precise experiment and theoretical proof will be presented in future work. In addition, the input of travel speed between two adjacent bus stops is assumed as instant, which can be formulated as a variable in the future work.

\section{Data Availability}

All data included in this study are available upon request by contact with the corresponding author.

\section{Conflicts of Interest}

The authors confirm that there are no conflicts of interest regarding the publication of this manuscript.

\section{Acknowledgments}

This work was supported by the National Natural Science Foundation of China (Grant nos. 71801153 and 71801149), Natural Science Foundation of Shanghai (Grant no. 
18ZR1426200), and Shanghai Innovation Training Program (Grant nos. XJ2020124 and SH2020069).

\section{References}

[1] M. Dessouky, R. Hall, A. Nowroozi, and K. Mourikas, "Bus dispatching at timed transfer transit stations using bus tracking technology," Transportation Research Part C: Emerging Technologies, vol. 7, no. 4, pp. 187-208, 1999.

[2] X. J. Eberlein, N. H. M. Wilson, and D. Bernstein, "The holding problem with real-time information available," Transportation Science, vol. 35, no. 1, pp. 1-18, 2001.

[3] C. F. Daganzo, "A cheap and resilient way to eliminate bus bunching," in Proceedings of the 4th International Conference on Future Urban Transport, Gothenburg, Sweden, 2009.

[4] J. J. Bartholdi III and D. D. Eisenstein, "A self-coördinating bus route to resist bus bunching," Transportation Research Part B: Methodological, vol. 46, no. 4, pp. 481-491, 2012.

[5] F. Delgado, J. C. Muñoz, and R. Giesen, "How much can holding and/or limiting boarding improve transit performance?" Transportation Research Part B: Methodological, vol. 46, no. 9, pp. 1202-1217, 2012.

[6] S.-X. He, "An anti-bunching strategy to improve bus schedule and headway reliability by making use of the available accurate information," Computers \& Industrial Engineering, vol. 85, pp. 17-32, 2015.

[7] S.-X. He, J. Dong, S.-D. Liang, and P.-C. Yuan, “An approach to improve the operational stability of a bus line by adjusting bus speeds on the dedicated bus lanes," Transportation Research Part C: Emerging Technologies, vol. 107, pp. 54-69, 2019.

[8] J. Argote-Cabanero, C. F. Daganzo, and J. W. Lynn, "Dynamic control of complex transit systems," Transportation Research Part B: Methodological, vol. 81, no. 1, pp. 146-160, 2015.

[9] L. Lynn, O. Cats, J. Gama, J. Mendes-Moreira, and J. F. de Sousa, "An online learning approach to eliminate Bus Bunching in real-time," Applied Soft Computing, vol. 47, pp. 460-482, 2016.

[10] W. Wu, R. Liu, and W. Jin, "Designing robust schedule coordination scheme for transit networks with safety control margins," Transportation Research Part B: Methodological, vol. 93, pp. 495-519, 2016.

[11] W. Wu, R. Liu, and W. Jin, "Modelling bus bunching and holding control with vehicle overtaking and distributed passenger boarding behaviour," Transportation Research Part B: Methodological, vol. 104, pp. 175-197, 2017.

[12] W. Wu, R. Liu, and W. Jin, "Integrating bus holding control strategies and schedule recovery: simulation-based comparison and recommendation," Journal of Advanced Transportation, vol. 2018, Article ID 9407801, 13 pages, 2018.

[13] G. Laskaris, O. Cats, E. Jenelius, M. Rinaldi, and F. Viti, "Multiline holding based control for lines merging to a shared transit corridor," Transportmetrica B: Transport Dynamics, vol. 7, no. 1, pp. 1062-1095, 2019.

[14] C. F. Daganzo, "A headway-based approach to eliminate bus bunching: systematic analysis and comparisons," Transportation Research Part B: Methodological, vol. 43, no. 10, pp. 913-921, 2009.

[15] C. F. Daganzo and J. Pilachowski, "Reducing bunching with bus-to-bus cooperation," Transportation Research Part B: Methodological, vol. 45, no. 1, pp. 267-277, 2011.

[16] Y. Xuan, J. Argote, and C. F. Daganzo, "Dynamic bus holding strategies for schedule reliability: optimal linear control and performance analysis," Transportation Research Part B: Methodological, vol. 45, no. 10, pp. 1831-1845, 2011.

[17] S. Liang, S. Zhao, C. Lu, and M. Ma, "A self-adaptive method to equalize headways: numerical analysis and comparison," Transportation Research Part B: Methodological, vol. 87, pp. 33-43, 2016.

[18] S. Zhang and H. K. Lo, "Two-way-looking self-equalizing headway control for bus operations," Transportation Research Part B: Methodological, vol. 110, pp. 280-301, 2018.

[19] S.-X. He, S.-D. Liang, J. Dong, D. Zhang, J.-J. He, and P.-C. Yuan, "A holding strategy to resist bus bunching with dynamic target headway," Computers \& Industrial Engineering, vol. 140, Article ID 106237, 2020.

[20] S. Liang, H. Zhang, M. Ma, and S. He, "Sensitivity analysis of fleet size for dynamic headway-based control method performance in terms of passengers' experience," Journal of Advanced Transportation, vol. 2020, Article ID 5070347, 16 pages, 2020.

[21] W. Suh, K.-S. Chon, and S.-M. Rhee, "Effect of skip-stop policy on a Korean subway system," Transportation Research Record: Journal of the Transportation Research Board, vol. 1793, no. 1, pp. 33-39, 2002.

[22] A. Sun and M. Hickman, "The real-time stop-skipping problem," Journal of Intelligent Transportation Systems, vol. 9, no. 2, pp. 91-109, 2005.

[23] M. M. O. Sidi, S. Hammadi, S. Hayat, and P. Borne, "Urban transport network regulation and evaluation: a fuzzy evolutionary approach," IEEE Transactions on Systems, Man, and Cybernetics - Part A: Systems and Humans, vol. 38, no. 2, pp. 309-318, 2008.

[24] C. E. Cortés, D. Sáez, F. Milla, A. Núñez, and M. Riquelme, "Hybrid predictive control for real-time optimization of public transport systems' operations based on evolutionary multi-objective optimization," Transportation Research Part C: Emerging Technologies, vol. 18, no. 5, pp. 757-769, 2010.

[25] D. Sáez, C. E. Cortés, F. Milla, A. Núñez, A. Tirachini, and M. Riquelme, "Hybrid predictive control strategy for a public transport system with uncertain demand," Transportmetrica, vol. 8, no. 1, pp. 61-86, 2012.

[26] F. Delgado, J. C. Muñoz, R. Giesen, and A. Cipriano, "Realtime control of buses in a transit corridor based on vehicle holding and boarding limits," Transportation Research Record: Journal of the Transportation Research Board, vol. 2090, no. 1, pp. 59-67, 2009.

[27] H. Zhang, S. Zhao, Y. Cao, H. Liu, and S. Liang, "Real-time integrated limited-stop and short-turning bus control with stochastic travel time," Journal of Advanced Transportation, vol. 2017, Article ID 2960728, 9 pages, 2017.

[28] H. Zhang, S. Liang, S. Zhao, and Q. Shang, "Advantages of bus stop skipping and holding control in reducing schedule deviation," Proceedings of the Institution of Civil Engineers-Municipal Engineer, pp. 1-10, 2019.

[29] W. Wu, R. Liu, W. Jin, and C. Ma, "Simulation-based robust optimization of limited-stop bus service with vehicle overtaking and dynamics: a response surface methodology," Transportation Research Part E: Logistics and Transportation Review, vol. 130, pp. 61-81, 2019.

[30] W. Wu, R. Liu, W. Jin, and C. Ma, "Stochastic bus schedule coordination considering demand assignment and rerouting of passengers," Transportation Research Part B: Methodological, vol. 121, pp. 275-303, 2019.

[31] S. Liang, M. Ma, and S. He, "Multiobjective optimal formulations for bus fleet size of public transit under headwaybased holding control," Journal of Advanced Transportation, vol. 2019, Article ID 2452348, 14 pages, 2019. 
[32] S. Liang, M. Ma, S. He, H. Zhang, and P. Yuan, "Coordinated control method to self-equalize bus headways: an analytical method," Transportmetrica B: Transport Dynamics, vol. 7, no. 1, pp. 1175-1202, 2019.

[33] Y. Bie, X. Xiong, Y. Yan, and X. Qu, "Dynamic headway control for high-frequency bus line based on speed guidance and intersection signal adjustment," Computer-Aided Civil and Infrastructure Engineering, vol. 35, no. 1, pp. 4-25, 2020.

[34] Y. Bie, D. Wang, and H. Qi, "Prediction model of bus arrival time at signalized intersection using GPS data," Journal of Transportation Engineering, vol. 138, no. 1, pp. 12-20, 2012.

[35] Y. Bie, X. Gong, and Z. Liu, "Time of day intervals partition for bus schedule using GPS data," Transportation Research Part C: Emerging Technologies, vol. 60, pp. 443-456, 2015.

[36] M. Ma and S. Liang, "An integrated control method based on the priority of ways in a freeway network," Transactions of the Institute of Measurement and Control, vol. 40, no. 3, pp. 843-852, 2018.

[37] M. Ma and S. Liang, "An optimization approach for freeway network coordinated traffic control and route guidance," PLOS One, vol. 13, no. 9, Article ID e0204255, 2018.

[38] H. Yu, D. Chen, Z. Wu, X. Ma, and Y. Wang, "Headway-based bus bunching prediction using transit smart card data," Transportation Research Part C: Emerging Technologies, vol. 72, pp. 45-59, 2016.

[39] H. Yu, Z. Wu, D. Chen, and X. Ma, "Probabilistic prediction of bus headway using relevance vector machine regression," IEEE Transactions on Intelligent Transportation Systems, vol. 18, no. 7, pp. 1772-1781, 2017.

[40] S. Liang, M. Ma, S. He, and H. Zhang, "Short-term passenger flow prediction in urban public transport: kalman filtering combined $K$-nearest neighbor approach," IEEE Access, vol. 7, pp. 120937-120949, 2019.

[41] G. Ma, M. Ma, S. Liang, Y. Wang, and Y. Zhang, "An improved car-following model accounting for the time-delayed velocity difference and backward looking effect," Communications in Nonlinear Science and Numerical Simulation, vol. 85, Article ID 105221, 2020.

[42] H. X. Liu, X. Wu, W. Ma, and H. Hu, "Real-time queue length estimation for congested signalized intersections," Transportation Research Part C: Emerging Technologies, vol. 17, no. 4, pp. 412-427, 2009.

[43] S. Liang, M. Ma, S. He, H. Zhang, and Z. Tang, "Influence of bus stop location on traffic flow," Proceedings of the Institution of Civil Engineers-Municipal Engineer, pp. 1-8, 2019.

[44] M. Ma, S. Liang, H. Guo, and J. Yang, "Short-term traffic flow prediction using a self-adaptive two-dimensional forecasting method," Advances in Mechanical Engineering, vol. 9, no. 8, 2017.

[45] M. Ma, S. Liang, and Y. Qin, "A bidirectional searching strategy to improve data quality based on $K$-nearest neighbor approach," Symmetry, vol. 11, no. 6, p. 815, 2019. 